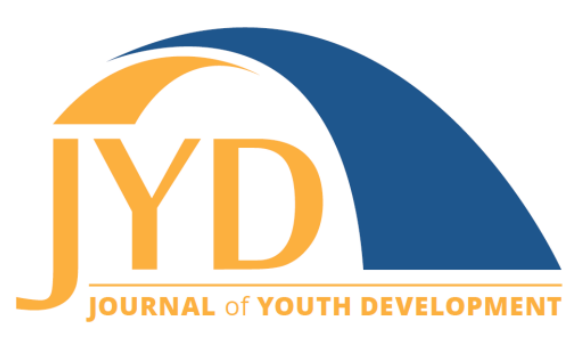

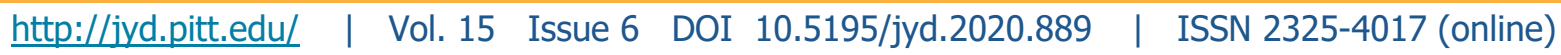

\title{
Effects of an After-School Program Focused on Physical Activity and Social-Emotional Learning
}

\author{
Caitlin Olive \\ University of New Mexico \\ caitlinrolive@unm.edu
}

Bryan A. McCullick

University of Georgia

bamccull@uga.edu

Phillip Tomporowski

University of Georgia

ptomporo@uga.edu

Karen Lux Gaudreault

University of New Mexico

kgaudreault@unm.edu

\section{Kelly Simonton}

University of Memphis

klsmnton@memphis.edu

\section{Abstract}

The purpose of this study was to analyze the influence of a 4-week, physical activity-infused socialemotional and character development (SECD) intervention on students'self-perceptions. Children ( $N=29)$ identified as "at risk" (The Great Schools Partnership, 2013) in Grades 2 through 5 who were enrolled in an after-school program participated in the study. A quasi-experimental design was used as children were placed into 2 groups at each after-school program (ASP) site. Data collection included student completion of the Social Emotional Learning Scale (SELS) prior to the intervention and the Social-Emotional Character Development Scale (SECD) pre- and post-intervention. $A 2 \times 2$ repeated measures analysis of covariance (RM-ANCOVA) was used to evaluate main effects and interactions among the independent variables (group and time) on the dependent variable (SECDS). Several covariates were also accounted for when analyzing differences including grade, gender, and students' baseline trait scores on the SELS. Although no statistical interactions were found, the trend in the data across the groups and grades does provide

(cc) EY New articles in this journal are licensed under a Creative Commons Attribution 4.0 License. This journal is published by the University Library System, University of Pittsburgh and is cosponsored by the University of Pittsburgh Press. The Journal of Youth Development is the official peer-reviewed publication of the National Association of Extension 4-H Youth Development Professionals and the National AfterSchool Association. 
Physical Activity and Social-Emotional Learning

information for the impact and feasibility of this type of program. More research is needed including interventions with longer duration and studies with larger sample sizes.

Key words: social-emotional learning, after-school programs, physical activity

\section{Introduction}

Sport and physical activity involvement have been seen as a vehicle through which children can learn a variety of skills that go beyond the gross motor skills required to engage in different activities. Many organized programs have begun advocating for social-emotional development as an outcome of sport participation (Gould \& Carson, 2008). According to the Collaborative for Academic, Social and Emotional Learning (CASEL) (2012), the primary focus of SEL is to develop children's ability to (a) understand and manage emotions, (b) set and achieve positive goals, (c) feel and show empathy for others, (d) establish and maintain positive relationships, and (e) make responsible decisions. Although similar to SEL, social-emotional and character development (SECD) is slightly different in that it focuses on character skills, such as management of emotions and truthfulness towards self and others (Berkowitz \& Grych, 2000; Eisenberg et al., 2004; King et al., 2005; Lerner et al., 2005; Park, Peterson, \& Seligman, 2004). Given that SEL and SECD skills are considered by many to be "life skills," this has led to the development of school-wide SEL programs where SEL is integrated into each class, including physical education. SECD skills can be learned both during and after school in various classroom and activity settings, including phyiscal activity. Studies have indicated that physical activity can be an effective medium for teaching SECD skills through the context of sports and games (Ciotto \& Gagnon, 2018).

Scholars have developed several measures of SEL and SECD in elementary-aged children. One instrument is the social-emotional and character development scale (SECDS) (Ji et al., 2013). SECD skills have been assessed in traditional classroom settings, but as of yet have not been measured in physical activity or physical education. Exploring the relaibility of a measure like this for elementary students would be paramount for measuring change in behaviors in programs focused on SEL and SECD. Therefore, the purpose of this study was to analyze the influence of a 4-week, physical activity-infused SECD intervention on students' SECD selfperceptions. 


\section{Physical Education and Physical Activity as Vehicles for SEL}

Physical education is seemingly a subject-matter area where SEL could be easily integrated as the nature of the physical education class provides inherent and easily created opportunities for students to practice skills that represent SEL (Ciotto \& Gagnon, 2018). For example, many physical education learning activities require students to work with partners and in groups whereby establishing and maintaining positive relationships. Furthermore, the majority of learning activities in physical education are goal-oriented and inundated with decision-making opportunities.

While physical education content is heavily laden with physical activity, it is important to note, that physical education and physical activity in after-school programs (ASPs) are not the same. Physical education is instructional time that involves pre-planning, instruction for skill development, appropriate tasks for deliberate skill practice, a lesson closure, and post-planning reflection. In ASPs, physical activity often looks like recess or student-choice activity. In order for SEL to be taught through physical activity, it has to be intentionally implemented into planned, structured physical activity, which can be done in physical education or an ASP with a physical activity focus. Without an intention to integrate SEL into a physical education or physical activity-focused ASP, children's SEL is left to chance. However, when SEL is an intentional part of a physical activity instructional context (like physical education or an ASP with a physical activity focus) it could provide the opportunity for children to learn SEL through planned and organized physical activity.

The idea of deliberately teaching SEL skills in physical education or through physical activity is hardly novel. Physical education scholars have used models like teaching personal and social responsibility ([TPSR]; Hellison, 2003) to teach students skills such as effort, persistence, and cooperation in physical education and physical activity contexts. While much research exists about the affective domain of learning and TPSR within physical education, there is still a need for research that focuses on measuring the development of SEL and SECD skills in physical activity of ASPs (Hellison, 2003).

\section{Social-Emotional Learning (SEL)}

CASEL (2012) defines SEL as

The processes through which children and adults acquire and effectively apply the knowledge, attitudes, and skill necessary to understand and manage emotions, 
set and achieve positive goals, feel and show empathy for others, establish and maintain positive relationship, and make responsible decisions (p. 4).

The purpose of SEL is to develop students' social-emotional comprehension, allowing them to encode, interpret, and reason social-emotional information (Lipton \& Nowicki, 2009). Accurate assessments of SEL programs are needed to ensure that intended improvements are occurring.

\section{SEL and After-School Programs}

After-school programs (ASPs) can provide varying activities for youth including socializing, academic enrichment, physical activity, crafts, music, and homework help (Halpern, 2002; Kremer et al., 2015; Vandell et al., 2005). ASPs have become more popular due to increased federal funding and have emerged as a way to support children's growth and development beyond academics (Hurd \& Deutsch, 2017; Roth et al., 2010). According to Hurd and Deutsch, "out-of-school settings, such as after-school programs (ASPs) and community organizations are natural sites for social and emotional learning (SEL) interventions" (2017, p. 96).

Many ASPs include a sport or physical activity component which makes them not only effective, but attractive to children. Sport and physical activity provide appropriate contexts to implement SEL through skill acquisition, teambuilding, and the experience of winning and losing, which align with SEL concepts (Gould \& Carson, 2008; Papacharisis et al., 2005; Wright et al., 2010). Research has indicated that adolescents tend to enjoy physical activity and sports and that this may contribute to maintaining student engagement in an ASP (Gordon et al., 2016; Kleiber et al., 1986; McCarthy et al., 2008). Despite this, little is known about the impact of SEL on physical activity and sports programs (Lubans et al., 2012).

Taken together, literature provides evidence to the implementation of SEL both within the traditional classrooms and in ASPs. To this point, however, SEL is just beginning to be implemented within physical education and physical activity. In order to ensure that SEL skills are being learned in ASPs and physical activity programs, it is important to conduct valid and reliable assessments. Currently, no questionnaire exists to assess SEL within physical activity contexts. Therefore, the purpose of this study was to analyze the influence of a 4-week, physical activity-infused SECD intervention on students' SECD self-perceptions. 


\section{Method}

An ASP titled the Physical Activity and Learning (PAL) Program served as the focus for this quasi-experimental design study. The PAL Program focused on developing SEL and on character development through the use of physical activity and sports for elementary-aged children identified as "at risk" by school personnel (Schwanenflugel \& Tomporowski, 2018). The criteria for "at-risk" included: parental welfare, parental employment status, socioeconomic status, limited transportation options, and parental education attainment. The PAL Program consisted of sites located at two elementary schools in a small urban school district in the southeastern United States. Site 2 was used as the control group and Site 1 as the experimental group. The lead author was the physical activity teacher at Site 1 . Students remained at the schools they attended due to transportation restrictions.

\section{Intervention}

The intervention took place during the physical activity and games (PAGs) portion of the ASP. The ASP was a federally-funded program conducted at two elementary schools. The daily schedule involved the following: the students began their program day at 2:35 P.M. with snack and homework time. The second and third graders were in one classroom and the fourth- and fifth graders were in another. At 3:30 P.M., all students moved to the gymnasium for PAGs. The final portion of the day, 4:30 to 5:30 P.M., was reading for the fourth- and fifth graders and math for the second and third graders.

Due to limited time, the PAGs lesson followed a modified version of Hellison's TPSR model (2003). A TPSR lesson includes the following components: relational time, awareness talk, physical activity, group meeting, and self-reflection time (Hellison, 2011). However, the SECD intervention lesson was as follows: awareness talk, SECD Activity 1, SECD Activity 2 (if time allowed), and a group meeting. The purpose of the SECD activities were to provide explicit and intentional opportunities for the students to practice using the SECD concepts presented during the awareness talk at the beginning of the lesson and again during the group meeting at the conclusion of the lesson. There were two teachers facilitating the PAGs portion of the PAL Program with one teacher at each of the sites. Both teachers had a teaching license in physical education and were second-year teachers in the PAL Program. Since the students, other PAL Program staff, and school staff were familiar with the two teachers, each teacher remained at their designated site. At Site 2, all routines and lesson plans remained the same for PAGs. 


\section{Fidelity Measures}

To ensure intervention fidelity, trained observers came once a week and used a checklist to ensure that all aspects of the SECD lesson were being met. There were two observers, both of whom worked for the PAL Program. Both observers were trained on how to use the checklist and rubric prior to data collection. Only one observer was present at a time. Each observer observed four lessons (33\%).

\section{Participants}

Participants in this study were second- through fifth-grade students enrolled in the PAL Program $(N=29)$ who were identified and recruited for the program because they were considered atrisk (according to previously mentioned factors) and were performing below grade level in reading, mathematics, or both. Some students $(n=7)$ had been in the program for multiple years; however, the majority $(n=22)$ entered the program the year of the study.

Participants at Site 1 ( $n=17$ ) included nine females and eight males and Site 2 had eight female and four male $(n=12)$ participants. With regards to the demographic information, the age range of the students was 7 to 12 years. A majority of the participants were either African American or Hispanic, with one student being Native American/Alaskan Native. It should be noted that this information was collected from the parents prior to the students' enrolling in the PAL Program.

\section{Fidelity to Lessons and Student Engagement}

This study was focused on the influence of a 4-week, physical activity-infused SECD intervention on students' SECD self-perceptions. There were 12 SECD lessons in the intervention group with four of these lessons (Lessons 5, 7, 10, and 12) being checked for fidelity using the SECDS Fidelity Checklist \& Rubric. Results (Table 1) indicated that fidelity to the intervention was strong. The instructor completed $96.42 \%$ of the SECD lesson items on average. For $75 \%$ of observed lessons, the instructor used only one SECD activity and therefore could complete a total of only seven items. However, in Lesson 7, the instructor used a second SECD activity and completed all eight items. Student engagement was rated on a 3-point scale: 1 (few students are engaged), 2 (some students are engaged), or 3 (most students are engaged). Engagement in Lesson 5 was scored out of 18 , due to the instructor missing an item (Questions Asked about Item); Lesson 7 was scored out of 24, due to the addition of the second SECD activity; and for Lessons 10 and 12, where seven items were completed, the 
maximum engagement score was 21 . Overall, the student engagement was high with an average of $90.08 \%$.

Table 1. Significance of Fidelity Measures and Student Engagement

\begin{tabular}{|l|c|c|}
\hline & \% of Items completed & \% of Student engagement levels \\
\hline Lesson 5 & $85.71 \%$ & $88.89 \%$ \\
\hline Lesson 7 & $100 \%$ & $91.67 \%$ \\
\hline Lesson 10 & $100 \%$ & $85.71 \%$ \\
\hline Lesson 12 & $100 \%$ & $95.24 \%$ \\
\hline Average & $96.42 \%$ & $90.08 \%$ \\
\hline
\end{tabular}

\section{Data Analysis Techniques}

All data were recorded using the Qualtrics survey tool and exported to Excel. Prior to analysis data were screened for accuracy and missing data. Only students who attended a minimum of 8 of the 12 lessons and who were present for pre/post data collection were included in analysis. Descriptive statistics and internal consistencies were analyzed using SPSS version 25 and recorded by each group and grade level (Table 2). A $2 \times 2$ repeated measures analysis of covariance (RM-ANCOVA) was used to evaluate main effects and interactions among the independent variables (group and time) on the dependent variable (SECDS). Several covariates were also accounted for when analyzing differences including grade, gender, and students' baseline trait scores on the SELS. Following a significant interaction or main effect, the post-hoc Fisher's LSD test was used to identify where differences occur. This method is preferred for uneven and small sample sizes (Tabachnick \& Fidell, 2013. Lastly, partial eta squared $\left(\eta_{p}{ }^{2}\right)$ was used to determine effect size for any significant interactions.

\section{Results}

\section{Descriptive Statistics}

Students' reported means and standard deviations for the SELS and the SECDS at Time 1 and Time 2 are provided on Table 2. Cronbach's alpha reliability scores for each the latent variable showed acceptable levels (>.70). Lastly, variable means were provided by grade level. Overall, the trait SELS variable showed a higher overall score for the intervention group to start with as opposed to the control group. Also, fifth graders reported the highest SELS mean score (4.01) 
while fourth graders reported the lowest (3.73). However, all grades reported mean scores that were over the midpoint for that scale suggesting a favorable belief, in general, about their social-emotional awareness and skills. Mean scores for both pre and post testing of SECDS showed declining trends amongst groups. Both groups reported less than the midpoint of the scale for their respected means. Also, overall means trended down from pre to post testing in both groups.

The RM-ANCOVA analyzed between and within interactions for the two groups from pre to post testing while accounting for covariance attributed to trait SELS, gender, and grade. There was not a significant interaction between the two groups across time (Wilks' $\Lambda=.964, F(1,22)=$ $0.819, p=.75, \eta_{\mathrm{p}}{ }^{2}=.04$, power $=.140$ ). Also, no within-group differences for any of the covariates were identified as significant although the group-by-grade interaction $(p=.09)$ was approaching significance. Due to a lack of interaction, no post-hoc examination was necessary. Also, given the general downward trend researchers did not expect a major interaction. However, when looking at mean differences, a sharper decline in SECDS mean scores is visible for the control group as compared to the intervention group. Another interesting trend was identified at the grade level. Each grade level showed a reduction in mean SECDS scores except for second graders, whose mean score increased from Time 1 to Time 2. Also, mean scores overall for second graders were quite high as compared to fifth-grade students, which corroborates the approaching significant $p$-value we identified.

Table 2. Means and Standard Deviations for All Latent Factors by Site and Grade

\begin{tabular}{|l|c|c|c|}
\hline & SELS & Pre-SECDS & Post-SECDS \\
\hline Intervention & $4.07(.252)$ & $1.60(.354)$ & $1.58(.467)$ \\
\hline Control & $3.60(.415)$ & $1.58(.369)$ & $1.52(.421)$ \\
\hline Total Mean & $3.89(.393)$ & $1.59(.353)$ & $1.56(.441)$ \\
\hline $2^{\text {nd }}$ & $3.82(.347)$ & $1.82(.397)$ & $1.91(.577)$ \\
\hline $3^{\text {rd }}$ & $3.93(.284)$ & $1.63(.374)$ & $1.59(.399)$ \\
\hline $4^{\text {th }}$ & $3.73(.601)$ & $1.53(.474)$ & $1.50(.444)$ \\
\hline $5^{\text {th }}$ & $4.01(.356)$ & $1.48(.195)$ & $1.39(.344)$ \\
\hline Cronbach's a & .758 & .877 & .935 \\
\hline Scale & $1-5$ & $1-4$ & $1-4$ \\
\hline
\end{tabular}




\section{Discussion}

The purpose of this study was to analyze the influence of a 4-week, physical activity-infused SECD intervention on students' SECD self-perceptions. The study results were used to evaluate both the potential impact of the program as well as the feasibility of its design and implementation. Although the intervention study focused on highlighting positive character development skills explicitly and intentionally, both programs were supporting youth in an afterschool setting and providing structured physical activity opportunities. Due to our lack of significant interactions between the two groups, it might be suggested that the 4-week intervention did not provide enough time for students to internalize the focus of SECD. Also, each group scored relatively high on SELS as a trait understanding of their emotional skills at the beginning of the program, which may have deterred the impact of the program on selfreported SECDS. Overall, the intervention group scored slightly higher at pre and post testing as compared to the control group. Finally, while statistically significant differences were not found, we speculate this may have been influenced by the small number of participants. Further research is needed involving this program to determine if statistical significance can be achieved with a larger sample size.

Each of the SELS and SECDS measurements was found to be reliable during this study. This supports previous literature, which validated this scale as a measure of elementary students' social and emotional learning (Coryn et al., 2009). The students' SELS scores established a baseline of social and emotional learning self-perceptions which allowed the researcher to account for students' predispositions when considering the potential growth during the pre and posttest of SECDS. Higher SELS scores and the lack of interaction in the intervention could be due to students' high awareness of their self-perceptions and an ability to assess themselves more accurately (Denham et al., 2009). It is interesting to note that the mean scores of perceived social-emotional skills were relatively high whereas personal character development at both time points were below the mid-point. One other possibility for the lack of interaction could be the inability for elementary students to view social and personal abilities as equal. Students may be pressured to be socially responsible on a regular basis but are given limited training about what it means to be personally responsible and exhibit high character. Lastly, it may simply be that elementary-age students cannot differentiate a structured youth program with games and sports from a program focused on personal and social responsibility. This is important information as it may inform future interventions. 


\section{Physical Activity and Social-Emotional Learning}

Another finding for design consideration and program feasibility is the dramatic differences in second- to fifth-grade views regarding SECDS. The decline in SECDS self-perceptions across the grade span aligns with previous findings that older elementary students had a decrease in SECDS due to an increase in problem behavior items (Carlo et al., 2007; Kokko et al., 2006; Washburn et al., 2011). It should be noted that the differences could be due to older students' abilities to discern between the components being measured with the SECDS (Ji et al., 2013). It may also imply that students face more SECD challenges as they get older (Washburn et al., 2011). Also, the SECD intervention could have allowed these students to have an increased understanding of their self-perceptions; therefore, it is possible that they answered the posttest SECDS more accurately based on their new-found knowledge. From an anecdotal perspective, researchers did view positive instances of character development in the intervention group when it came to the use of newly learned character development language and case-by-case situations of self-analyzation. Thus, a mixed-methods approach to evaluating student change along with a longer, more extensive program may be recommended.

\section{Limitations}

This quasi-experimental study had some limitations. As Ji and colleagues (2013) noted, the impact of self-report on the validity is a concern, especially given the focused age range of this program. It should also be noted that the SECDS has a reading grade level of 3.4, which may have resulted in inaccurate scores due to participants' not fully understanding items. In an attempt to mitigate this issue, the researchers did read the items aloud to students and explained terms if students did not understand; however, it is still possible that some students misunderstood the items. Also, future research may be necessary to evaluate potential change in character development awareness from early- to late-elementary students.

A second limitation of the study is the selected population of underserved youth; findings from this study have limited transferability to different populations. A third limitation of this study is the sample size as the PAL Program permits only selected underserved students with a maximum roster of 60 children. This is partially due to trying to maintain the required staff-tostudent ratio between $1: 10$ and $1: 15$ on a grant budget (Chung, 2000). This resulted in the sample size of 29 students from only two elementary schools. It would be optimal to have an equal and larger number of students for each treatment, as well as to mix the students. It should be noted that differences found between the two groups may not be solely due to the intervention alone, as other factors such as school settings and teachers may influence results. 


\section{Implications for Practice and Future Research Directions}

The results of this study have implications for the feasibility and impact of constructing SECD into structured physical activity and physical education. SEL is often disregarded in these settings, although national standards for physical education include the affective domain of learning as an essential outcome (Ciotto \& Gagnon, 2018; Society of Health and Physical Educators, 2013, 2019). This domain covers topics like the ones included in the SELS and SECDS. Addressing SECD in physical education is not a matter of adding content to the curriculum but changing the way physical educators teach this content to students. In doing so, physical education can provide an opportunity for a more well-rounded education, which will enhance students' social-emotional skills. Currently, physical education and structured physical activity are behind other subject areas relative to implementation of SECD and SEL into the classroom (Durlak et al., 2011), and further research should focus on the influence of physical activity on students' social-emotional skills.

Future studies should focus on implementing a SECD-infused physical activity intervention with a larger sample size, which may result in more statistically significant findings. Special focus on the programs curriculum for younger and older students in elementary school may need special attention. In addition, the development of a simplified instrument would enhance subsequent research in this area. Finally, we suggest increasing the duration of SECD interventions. Our results indicate and we speculate that it may be necessary to have more lessons for several weeks for students' SECD self-perceptions to change. It is important to note that physical education has long been a place for teaching physical skills, but an additional focus on student personal responsibility (Hellison, 2003) and social responsibility such as sportspersonship (Lambdin, 1995) is needed, particularly for at-risk youth. Because of this, promoting and teaching SECD and SEL concepts in structured physical activity settings should not be perceived as additional work for teachers, but rather teachers' improving their language and methods of instruction to provide a more holistic and well-rounded experience.

\section{References}

Berkowitz, M. W., \& Grych, J. H. (2000). Early character development and education. Early Education and Development, 11, 55-72. https://doi.org/10.1207/s15566935eed1101 4

Carlo, G., Crockett, L. J., Randall, B. A., \& Roesch, S. C. (2007). A latent growth curve analysis of prosocial behavior among rural adolescents. Journal of Research on Adolescence, 17(2), 301324. https://doi.org/10.1111/j.1532-7795.2007.00524.x 
Chung, A.-M. (2000). After-school programs: keeping children safe and smart. U.S. Department of Education, Office of Educational Research and Improvement, Educational Resources Information Center.

Ciotto, C. M., \& Gagnon, A. G. (2018). Promoting social and emotional learning in physical education. The Journal of Physical Education, Recreation \& Dance, 89(4), 27-33. https://doi.org/10.1080/07303084.2018.1430625

Collaborative for Academic, Social, and Emotional Learning. (2012). 2013 CASEL guide: Effective social and emotional learning programs (Preschool and elementary school edition). Author.

Coryn, C. L. S., Spybrook, J. K., Evergreen, S. D. H., \& Blinkiewicz, M. (2009). Development and evaluation of the social-emotional learning scale. Journal of Psychoeducational Assessment, 274), 283-295. https://doi.org/10.1177/0734282908328619

Denham, S. A., Wyatt, T. M., Bassett, H. H., Echeverria, D., \& Knox, S. S. (2009). Assessing socialemotional development in children from a longitudinal perspective. Journal of Epidemiology and Community Health, 63, 137-152. http://dx.doi.org/10.1136/jech.2007.070797

Durlak, J. A., Weissberg, R. P., Dymnicki, A. B., Taylor, R. D., \& Schellinger, K. B. (2011). The impact of enhancing students' social and emotional learning: A meta-analysis of school-based universal interventions. Child Development, 82(1), 405-432. https://doi.org/10.1111/j.14678624.2010.01564.x

Eisenberg, N., Champion, C., \& Ma, Y. (2004). Emotion-related regulation: An emerging construct. Merrill-Palmer Quarterly, 50, 236-259.

Gordon, B., Jacobs, J. M., \& Wright, P. M. (2016). Social and emotional learning through a teaching personal and social responsibility based after-school program for disengaged middle-school boys. Journal of Teaching in Physical Education, 35(4), 358-369. https://doi.org/10.1123/itpe.2016-0106

Gould. D., \& Carson, S. (2008). Life skills development through sport: current status and further directions. International Review of Sport and Exercise Psychology, 71 ), 58-68. https://doi.org/10.1080/17509840701834573

The Great Schools Partnership. (2013). The Glossary of Education Reform. https://www.edglossary.org/at-risk/

Halpern, R. (2002). A different kind of child development institution: the history of after-school programs for low-income children. Teachers College Record, 104, 178-211.

Hellison, D. (2003). Teaching responsibility through physical activity ( $2^{\text {nd }}$ ed.). Human Kinetics. Hellison, D. (2011). Teaching responsibility through physical activity ( $3^{\text {rd }}$ ed.). Human Kinetics. Hurd, N., \& Deutsch, N. (2017). SEL-focused after-school programs. Future of Children, 271), 95-115. 
Ji, P., DuBois, D. L., \& Flay, B. R. (2013). Social-emotional and character development scale: development and initial validation with urban elementary school students. Journal of Research in Character Education, 9(2), 121-147.

King, P. E., Dowling, E. M., Mueller, R. A., White, K., Schultz, W., Osborn, P., Dickerson, E., Bobek, D. L., Lerner, R. M., Benson, P. L., \& Scales, P. C. (2005). Thriving in adolescence: The voices of youthserving practitioners, parents, and early and late adolescents. The Journal of Early Adolescence, 25, 94-112. https://doi.org/10.1177/0272431604272459

Kleiber, D., Larson, R., \& Csikszentmihalyi, M. (1986). The experience of leisure in adolescence. Journal of Leisure Research, 18(3), 169-176. https://doi.org/10.1080/00222216

Kokko, K., Tremblay, R. E., Lacourse, E., Nagin, D. S., \& Vitaro, F. (2006). Trajectories of prosocial behavior and physical aggression in middle childhood: Links to adolescent school dropout and physical violence. Journal of Research on Adolescence, 16(3), 403-428.

https://doi.org/10.1111/j.1532-7795.2006.00500.x

Kremer, K., Maynard, B., Polanin, J., Vaughn, M., \& Sarteschi, C. (2015). Effects of after-school programs with at-risk youth on attendance and externalizing behaviors: A systematic review and metaanalysis. Journal of Youth \& Adolescence, 44(3), 616-636. https://doi.org/10.1007/s10964-014$\underline{0226-4}$

Lambdin, D. (1995). Sport education: quality PE through positive sport experiences. Journal of Teaching in Physical Education, 15(1), 130-132.

Lerner, R. M., Lerner, J. V., Almerigi, J. B., Theokas, C., Phelps, E., Gestsdottir, S., Naudeau, S., Jelicic, H., Alberts, A., Ma, L., Smith, L. M., Bobek, D. L., Richman-Raphael, D., Simpson, I., Christiansen, E. D., \& von Eye, A. (2005). Positive youth development, participation in community youth development programs, and community contributions of fifth-grade adolescents: Findings from the first wave of the 4-H study of positive youth development. The Journal of Early Adolescence, 25, 17- 71. https://doi.org/10.1177/0272431604272461

Lipton, M., \& Nowicki, S. (2009). The social emotional learning frame-work (SELF): a guide for understanding brain-based social emotional learning impairments. Journal of Developmental Processes, 4, 99-115.

Lubans, D. R., Plotnikoff, R. C., \& Lubans, N. J. (2012). A systematic review of the impact of physical activity programmes on social and emotional well-being in at-risk youth. Child and Adolescent Mental Health, 171), 2-13. https://doi.org/10.1111/j.1475-3588.2011.00623.x

McCarthy, P. J., Jones, M. V., \& Clark-Carter, D. (2008). Understanding enjoyment in youth sport: A developmental perspective. Psychology of Sport and Exercise, 9(2), 142156. https://doi.org/10.1016/j.psychsport.2007.01.005 
Papacharisis, V., Goudas, M, \& Theodorakis, Y. (2005). The effectiveness of teaching a life skills program in a sport context. Journal of Applied Sport Psychology, 77(3), 247-254.

\section{https://doi.org/10.1080/10413200591010139}

Park, N., Peterson, C., \& Seligman, M. E. P. (2004). Strengths of character and well-being. Journal of Social \& Clinical Psychology, 23, 603-619. https://doi.org/10.1521/jscp.23.5.603.50748

Roth, J. L., Malone, L. M., \& Brooks-Gunn, J. (2010). Does the amount of participation in afterschool programs relate to developmental outcomes? A review of the literature. American Journal of Community Psychology, 45, 310-324. https://doi.org/10.1007/s10464-010-9303-3

Schwanenflugel, P. J., \& Tomporowski, P. D. (Eds.). (2018). Physical activity and learning after school. Guilford.

Society of Health and Physical Educators. (2013). National Standards for K-12 Physical Education. SHAPE America.

Society of Health and Physical Educators. (2019). Crosswalk for SHAPE America national standards \& grade-level outcomes for $K-12$ physical education and CASEL social and emotional learning core competencies. SHAPE America.

Tabachnick, B. G., \& Fidell, L. S. (2013). Using multivariate statistics ( $6^{\text {th }}$ ed.). Pearson Education Limited.

Tolmie, A., McAteer, E., \& Muijs, D. (2011). Quantitative methods in educational and social research using SPSS. McGraw-Hill Education.

Vandell, D. L., Shernoff, D. J., Pierce, K. M., Bolt, D. M., Dadisman, K., \& Brown, B. B. (2005). Activities, engagement, and emotion in after-school programs (and elsewhere). New Directions for Youth Development, 105, 121-129. https://doi.org/10.1002/yd.111

Vetter, T. R. (2017). Descriptive statistics: reporting the answers to the 5 basic questions of who, what, why, when, where, and a sixth, so what? Anesthesia and Analgesia, 125(5), 1797-1802. https://doi.org/10.1213/ANE.0000000000002471

Washburn, I. J., Acock, A., Vuchinich, S., Snyder, F., Li, K. K., Ji, P., Day, J., Dubois, D., \& Flay, B. R. (2011). Effects of a social-emotional and character development program on the trajectory of behaviors associated with social-emotional and character development: Findings from three randomized trials. Prevention Science, 12, 314-323. https://doi.org/10.1007/s11121-011-0230-9

Wright, P. M., Li, W., Ding S., (2010). Integrating a personal and social responsibility program into a wellness course for urban high school students: assessing implementation and educational outcomes. Sport, Education and Society, 15(3), 277-298. https://doi.org/10.1080/13573322.2010.493309 